\title{
The Cultural Transformation of Large Chinese Enterprises into Internationally Competitive Corporations: Case Studies of Haier and Huawei
}

\author{
Colin Hawes \\ Senior Lecturer, Faculty of Law \\ University of Technology Sydney, Australia \\ and \\ Eng Chew \\ Professor, School of Systems, Management and Leadership \\ University of Technology Sydney, Australia
}

[Accepted for publication and subsequently published in Journal of Chinese Economic and Business Studies 9.1: (Feb. 2011) 67-83]

Correspondence address:

Colin Hawes

1310 Glen Abbey Drive

Burnaby, B.C.

CANADA. V5A 1E3 


\begin{abstract}
:
The Chinese government has recently introduced a policy requiring all large Chinese business corporations to transform their corporate cultures with the aim of increasing their competitiveness on the international stage. This paper traces the origins of the policy to the outstanding performance of a small number of Chinese firms since the late 1980s, a phenomenon attributed by the CEOs of these firms to effective implementation of cultural values change among their workforces. We give detailed accounts of two such firms, Haier Group and Huawei Technologies, demonstrating how they have utilized cultural management techniques to improve their employees' performance. We also identify some negative aspects of their approach to cultural management that may impede these firms in their efforts to become truly international corporations.
\end{abstract}

Keywords: China - Corporate Culture - Haier - Huawei - Management Internationalization

JEL Classifications: M14 Corporate Culture; and P31 Socialist Enterprises and Their Transitions

Total Word Count (including title page, notes, references, and abstract): 8,064 


\section{Introduction:}

In recent years, there has been a dramatic increase in the attention paid to corporate culture (qiye wenhua) by the Chinese government and by large Chinese business firms. In 2005, the Chinese State-owned Assets Supervision and Administration Commission of the State Council (SASAC), a government body which supervises the 125 largest corporate groups under Central Government control, issued a policy requiring all Chinese state-controlled firms to "strengthen and build” their corporate cultures (SASAC 2005). Subsequently, in 2006, the Chinese Ministry of Labor and Social Security approved a new professional designation of Corporate Culture Officer, which will require all large Chinese firms to select staff to take intensive courses and exams in corporate culture transformation before they can obtain a formal qualification to engage in this kind of work (Zhonghua qiye wenhua wang 2006). The Chinese government has also sponsored various corporate culture conferences at national and local levels, and subsidized corporate culture training for thousands of Chinese corporate executives (Zhongguo qiye wenhua yanjiuhui 2003-).

Likewise, over the past decade, the vast majority of China’s largest corporations and conglomerates have set up corporate culture programs. A survey of the top three hundred Chinese corporations or corporate groups by asset size reveals that almost $90 \%$ of them include references to corporate culture programs on their websites, as do $79 \%$ of the top two hundred privately-managed corporations (minying qiye). ${ }^{1}$ It is striking to find this broad consensus among so many state-and privately-controlled corporations covering the

\footnotetext{
${ }^{1}$ Survey of corporate websites carried out by one of the authors in 2007, and updated in 2009.
} 
full gamut of industrial sectors from steel-making, chemicals, and automobile production to real estate development, financial services, and food retailers.

Clearly the corporate culture phenomenon is a significant development in China, exerting a major influence on the management of the largest Chinese business firms, and becoming a significant topic of inquiry among Chinese management scholars. ${ }^{2}$ However, it has been almost completely neglected in the English-language literature on Chinese management. Some case studies have briefly noted that corporate culture is part of Chinese firms' reform strategies, but they have not given much indication of what this “culture” actually means. For example, Teagarden and Cai $(2009,76)$, in case studies of four successful Chinese corporations, state that in their learning phases of development, all four firms had to "build [their] vision and values" and "establish [their] corporate culture.” But no explanation is provided as to how they did this, and corporate culture is seen as just one, apparently minor, aspect of these firms' development. Likewise, Thomas W. Lin in three detailed and useful studies of the Haier Group’s management approach, does mention the importance of the firm's “enterprise culture,” and even lists Haier’s “core values” (Lin 2005, 2), but he attributes Haier’s success largely to incentive systems associated with its customer-centered human resource and operations management strategies: "the OEC management control system, unique performance management systems, and the market-chain-based business process re-engineering system” (Lin 2009,

\footnotetext{
${ }^{2}$ In 2008 the online catalogue at the National Library of China listed 911 books containing 企业文化 qiye wenhua (corporate culture) in their titles, of which over 400 were published since 1999. The CNKI China Academic Journals database reveals a steady increase in the number of articles with qiye wenhua in their titles published each year: 0 for 1985 and earlier; 10 for 1986; 696 for 1996; 2824 for 2006; and 3661 for 2008.
} 
49; cf. Lin 2006). These are only one part of Haier's corporate culture, as we demonstrate below.

Other articles give brief overviews of the main characteristics of Chinese corporate, or "enterprise,"3 culture based on broad surveys, but they do not provide detailed analysis of individual firms (Cooke 2008; Tsui, Wang \& Xin 2006; Xin et al 2002). Indeed, one of these studies noted a "void" in the literature on how corporate culture is perceived to work in China (Cooke 2008, 294). ${ }^{4}$

In this paper, we will begin to correct the neglect of this topic by scholars writing in English. We will describe the cultural management techniques adopted by two of China's most successful large corporations, and the key role of their CEOs in promoting the cultural management approach. This section of the paper is based on the firms' own published documents, including firm websites, CEOs’ speeches, and authorized publications, as well as secondary accounts by Chinese management scholars. Then we will provide a critique of these firms' cultures, identifying the negative consequences of their management styles, focusing especially on issues relating to employee morale and internationalization. We conclude that both firms will need to adjust their cultural values in significant ways in order to sustain their performance and become truly internationalized corporations.

\footnotetext{
${ }^{3}$ We prefer to use the more common English term corporate culture, rather than enterprise culture, which is a more literal translation of the Chinese qiye wenhua.

${ }^{4}$ We are not concerned in this article with so-called cross-cultural management approaches, which draw distinctions between national cultures rather than individual firm cultures. There is an extensive scholarly literature on cross-cultural management, for which see Smith et al 2008; X. Zhang 2009.
} 


\section{Corporate Culture Defined}

To understand how Chinese firms have transplanted what was originally a foreign management concept, we must first briefly explain what corporate culture means and where it came from. Corporate culture as a field of study took off in the early 1980s in the United States as a response to the Japanese economic “threat” (Ouchi 1981). Deal and Kennedy (1982, 5), amongst others, identified “strong” or "positive” corporate cultures as the main reason for the sustainable and successful business performance of both Japanese and outstanding American firms.

The typical feature that distinguishes the corporation with a "strong" culture from its mediocre peers is its strong set of shared values (Deal and Kennedy 1982, 22). These corporate values need not be detailed or complicated. The most important thing is to ensure that they "are a reality in the minds of most people throughout the company, not just the senior executives” (Deal and Kennedy 1982, 23).

Corporate culture theorists note that these values often stem from the vision and personal example of the firm's founder(s), and so the values are frequently illustrated using “stories” or "myths" about these founders (Schein 1985, ch.10). Alternatively, the values may be underscored by the behavior of exceptional employees or managers, so-called corporate "heroes.” Such heroes must be consciously celebrated - and their work publicized - to guide and inspire other employees to embrace the firm's values (Deal and Kennedy 1982, ch.3). 
In theory, through promoting a set of positive values among their employees, corporations will be able to change their mindset and make them more committed to their work. Employees will then volunteer their best for the corporation, and there will be little need for external rules and discipline (Ouchi 1981, 81, 83).

Another practice that distinguishes the culture of "excellent" corporations is their conscious use of “rites and rituals” to give employees a sense of belonging and make their work meaningful (Deal and Kennedy 1982, 63). These rituals include awards ceremonies, social events, and various opportunities for employees and managers to communicate with each other and feel a sense of collective cohesion (Deal and Kennedy 1982, 64-75).

Finally, corporate culture texts invariably assert that successful corporations adapt and continually improve their cultures in response to changes in the external business environment. A "successful” manager should be able to use the various cultural techniques mentioned above to transform a "negative" corporate culture into a positive one that improves employee performance and productivity (Kilmann, Saxton \& Serpa 1986, ch. 12-19).

Of course, besides the various social indoctrination methods noted above, the senior management must also ensure that the firm's formal incentive systems follow the new cultural norms and suppress the old ones, so that "social energy" and the "formal system" 
will work together to make the organization succeed (Kilmann, Saxton \& Serpa 1986, 369).

Since the 1980s, scholars have identified major flaws in the assumptions of these early corporate culture proponents (Parker 2000, 15-26; Sheldrake 2003, 200-3). Yet many business executives seem to believe there are tangible benefits in applying a cultural approach to leadership. Large American and Australian firms, for example, expend significant resources on typical "cultural management" techniques such as diagnosing or adjusting the firm's "values," "vision," and "mission statement”; organizing firm “rituals”; and celebrating corporate "heroes” (Frankel 2007; Jones et al 2006). And as we noted above, Chinese business leaders have also embraced the concept of corporate culture in increasing numbers and applied it to their firms, claiming that it has resulted in dramatic improvements in business performance.

\section{Cultural Management Techniques at Haier and Huawei}

In this section, we will demonstrate how two well-known Chinese firms, Haier Group and Huawei Technologies, have adopted various techniques of corporate culture transformation in an attempt to improve their performance. We have selected these firms for two main reasons. 
First, they have both achieved remarkable sustained growth over the past two or more decades, and are clearly among the most successful and internationally competitive Chinese business firms today. In 1984, when Zhang Ruimin became director of the firm that later became Haier Group, it was a money-losing, inefficient, collectively-owned refrigerator factory. Now, Haier is China's best known manufacturer of home appliances with widespread name recognition in the West. It has more than 50,000 employees throughout the world and its reported 2008 global revenue was RMB122 billion yuan (Haier, n.d.(a)). Huawei Technologies, a privately-controlled firm, was founded by Ren Zhengfei and six partners in 1988 to import foreign technology and assemble simple telephone switch products for the domestic market (G. Zhang 2007, 23-4, 135, 223-4). Huawei now dominates the Chinese market for wireless telecommunications equipment, and has expanded its business to over 100 countries, competing with multinationals like Cisco and Lucent-Alcatel. By 2008, around 75\% of its 129 billion yuan sales revenues came from overseas markets rather than from China (Huawei n.d.(a) and (b)).

Second, the CEOs of these two firms, Zhang Ruimin and Ren Zhengfei have consistently underscored the crucial importance of cultural transformation for the success of their firms in an increasingly competitive and internationalized business environment. For example, Zhang Ruimin has stated:

Corporate culture is ... the soul of a corporation. If a corporation lacks its own culture, it may be able to grow fast for a short period, but it will lack stamina and won’t last long (R. Zhang, 1998, 340). 
And Ren Zhengfei has declared:

Resources are limited; only culture renews itself unceasingly. ... Huawei does not have natural resources that it can rely on, so it can only depend on the enormous 'oil fields,' 'forests' and 'mines' that are found inside peoples' minds (Huawei Technologies 1998, art.6).

The cultural transformation techniques as applied by Haier and Huawei can be conceptualized into a framework of five interrelated levels (as shown in Figure 1): (A) defining the corporate philosophy and values; (B) creating corporate "myths" that shock employees into a realization of the importance of the firm's values; (C) setting up rituals to celebrate the firm's heroes and to publicly criticize those who fail to embrace the firm's values; (D) fixing the values in place, in other words, getting all employees to internalize the values with financial incentives, management systems and process reengineering; and finally, (E) leading by example, ensuring that the CEO is subject to the same values as everyone else in the firm. While the details may differ, the Haier and Huawei methodologies bear a close resemblance to the broad patterns of "successful" corporate culture transformation of corporations reported in other studies (e.g. Jones et al 2006; Kilmann et al 1986). 


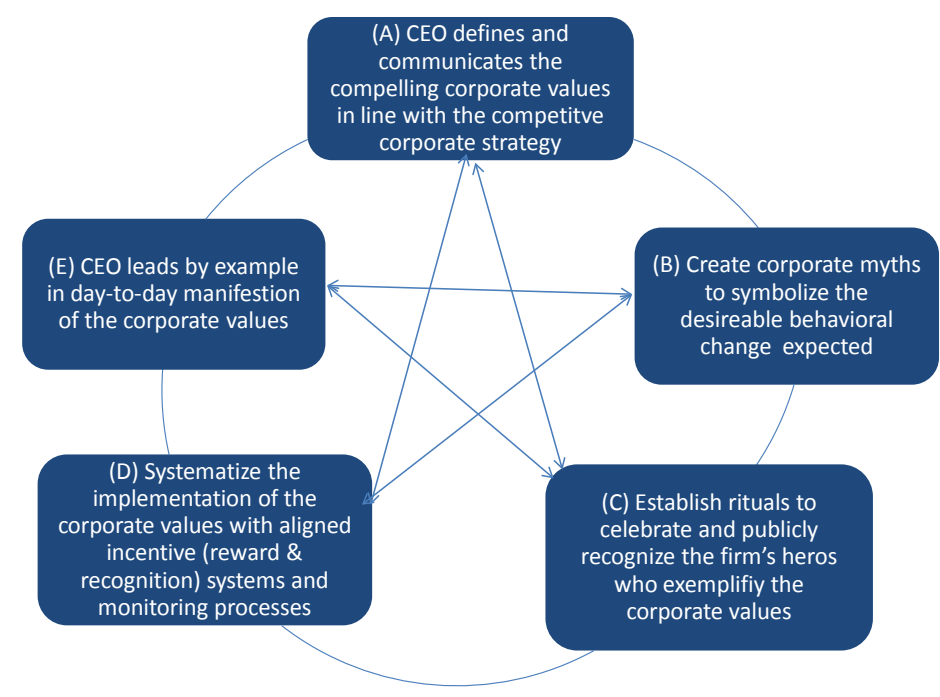

Figure 1: Haier’s and Huawei’s Framework for Cultural Transformation

The following subsections analyze these five levels in more detail.

A. Defining the corporate philosophy and values

The core philosophy and values of these two firms are simple, but were innovative in the Chinese business environment of the 1980s and1990s (Tung 1982, 66-8; Jackson 1992, 114-20). Haier has embraced the values of quality and "zero defects" since the 1980s, and has also consistently promoted the value that the customer is always right, and there should be "zero distance” between Haier's employees and its customers. Finally, Haier constantly states that innovation, whether of technology or of business processes, is key to its success, allowing Haier to create its own brand and stay ahead of the competition in China and overseas (Haier n.d.(b); and Luo et al, 2006, 344-61). 
The values of Huawei Technologies are similar in substance to those of Haier, both companies being fiercely market and customer driven, although Huawei expresses these values in a slightly different way. It advocates constant "self-criticism," "hard struggle," and "study" to improve the quality of the firm's products and technology. Huawei's employees are the only thing that separates the firm from total collapse; they need to constantly innovate to stay ahead of the competition. And Huawei's employees must develop a "culture of service" to customers, ensuring that everything they do improves Huawei's market position. If a product has no market value, it is a useless product (Z. Ren 1996a, b; 1997b; Huawei Technologies 1998, arts. 6, 8, 25).

While the values that Haier and Huawei promote exhibit similarities to each other and to those of numerous other firms, both have adopted interesting methods to implement these values, beginning with some distinctive corporate "myths."

B. Creating corporate myths to underscore the firm's values

According to the corporate culture theorists, a corporate myth is a story about the firm's CEO and/or employees that shows the firm's core values being put into practice in a memorable and vivid, even shocking, way. Through the initial event, and through subsequent repetition in speeches, firm publications, and informal conversations, the 
story spreads to all current and future employees, motivating them to emulate the example and improve their performance (Schein 1985, ch.10).

The most famous myth at Haier is the fridge smashing incident. In 1985, customers complained about the poor quality of refrigerators made by the firm. Zhang Ruimin, then factory manager, found that 76 refrigerators in the warehouse were defective. Some proposed that these refrigerators be sold to employees at a discount, as was common practice among other Chinese enterprises at that time. But Zhang Ruimin made an "unreasonable" decision that these refrigerators should be destroyed in public by the workers who made them. Zhang even took up a sledgehammer to participate in the smashing. This reinforced the message that poor quality products would not be tolerated by the management. This episode could have been forgotten after a few years, as Haier subsequently became a highly successful fridge manufacturer by the early 1990s. But it has been constantly repeated in Zhang Ruimin's speeches, on the firm's website, and in the firm's training sessions for new employees even down to the present (R. Zhang 1998; 2000a; 2003; 2008; and Haier, n.d.(c)). There is no doubt that Zhang Ruimin wants this event to be a "mythical" illustration of the importance of continually improving quality for Haier's success.

Ren Zhengfei at Huawei has also made effective use of shocking mythical events to underscore the firm's cultural values. For example, in 1996 he suddenly introduced a requirement that all Huawei's sales and marketing staff, including all managers and the divisional director, had to resign en masse and then reapply for their jobs in a competitive 
hiring process. Around 30\% failed to get rehired or were demoted from managerial positions to the rank and file (Z. Ren 1996b; Wu 2004). Ren Zhengfei emphasized the "mythical" meaning of this event in several speeches over the next few years, declaring that it was absolutely essential to constantly renew the workforce and remove underperforming staff at all levels (Z. Ren 1997a; cf. Z. Ren 1996b and Wu 2004). The firing and rehiring exercise was repeated in late 2007, when some 7000 long-serving Huawei employees were required to resign and reapply for their jobs (Jiang and Li 2007; Anon. 2007a).

Another Huawei myth originated at an "awards ceremony” that Ren Zhengfei arranged in 2000. The awards presented to various employees included rejected products that had failed in the market, for which the "winning employee" had been responsible, or copies of unnecessary expenses claims by “winning employees” that had wasted the firm's money (Z. Ren 2000a). Addressing the employees, Ren declared: “The reason why we are making this into such a big spectacle is to carve it deeply into your hearts, knowing that it will be passed down through the generations.... Only through constant selfcriticism will we be able to mature quickly.” (Z. Ren 2000a).

Space does not permit a detailed examination of several other myths that these two firms have cultivated over the years, each one designed to underscore the crucial importance of core values or new values that they are seeking to introduce. The key point to note is the conscious repetition of the significance of the original mythical event over the years so that its cultural meaning is "carved deeply" into the hearts of all employees. 
C. Setting up rituals to celebrate heroes and criticize laggards

A related topic to corporate myths is rituals. While myths tend to record single defining events, rituals are more mundane regular practices that seek to inculcate the firm's values, and to show that it is not just the CEO but everybody who can exemplify the firm's spirit. There may be some overlap between myths and rituals. For example, after Ren Zhengfei arranged the "reject awards" at Huawei and called for everyone to engage in "self-criticism," the firm then set up a regular quarterly "democratic meeting” where the employees of each division of the firm would have to engage in self-criticism of their own work and of the firm's products and processes. Managers would also have to do selfcriticism in front of their employees, and those who refused to do so would be demoted (Z. Ren 2000a; Luo et al 2006, 413; Zhao 2005). Enforcing the involvement of managers in this ritual was designed to overcome the common Chinese fear of "losing face." (Z. Ren 2001; Luo et al 2006, 414).

The Haier Group has developed a similar ritual for its employees to remind them of the importance of quality performance. At the start of every shift, supervisors stand on a large pair of footprints drawn on the factory floor and give a brief pep talk to their work group. At the end of the shift, employees in each work group gather beside the footprints again. Those employees who have performed worst that day must stand on the footprints and listen to criticism of their faults. The best-performing employees then stand on the 
footprints, and they explain how they managed to achieve their outstanding performance that day (Yi and Ye 2002, 49-50; Lin 2006, 51).

Both Haier and Huawei hold regular prize ceremonies for employees and managers who have performed well; and employees are frequently celebrated in these firms' corporate magazines and public speeches for proposing positive ideas to increase profits, save costs and improve efficiency. Their CEOs often praise these top performers as corporate "heroes” (Z. Ren 1997a).

Another kind of ritual that is particularly promoted at Haier is to encourage employees to draw cartoons and create other artistic or calligraphic works that express the firm's cultural values. Prizes are given for creations that sum up the values in an innovative and entertaining way, and they are posted on the firm's website and around its factories and offices. While this exercise may seem only vaguely related to their work, it ensures that employees are actively thinking about the meaning of the firm's values and how they might be applied, rather than just passively reading the values in a dry corporate culture manual produced by senior management (R. Zhang 2003; Haier n.d.(d)).

As noted above, many of Haier's and Huawei's rituals are reported in their in-house magazines, and these magazines are also used as a central forum for discussing how best to implement the firms' cultural values, and to report on successful examples of the values in practice (see Liu 2006, 169-70). Both Haier’s and Huawei's magazines also include regular articles by employees in which they describe how their lives and working 
habits have been positively impacted by their firm's culture. As one report on Huawei sums up: "Huawei People is a publication that everyone within Huawei must read. It is not just a source of information; more importantly, it is the frontline for spreading Huawei’s culture” (Zhao 2005).

This kind of positive and negative reinforcement through rituals, public celebrations, and public criticisms provides a non-financial incentive for employees to embrace the firm's values. At the same time, neither Haier nor Huawei are blind to the power of financial incentives, and both firms have expended a great deal of time and effort to develop more systematic incentive programs and processes that are aligned with their core values, as the next section demonstrates.

D. Fixing the values in place with training programs, incentives, systems and processes

Haier is famous for developing an arrestingly strict employee performance evaluation process called the OEC system. 'O' stands for overall - in other words, over the whole firm; ' $E$ ' stands for every task, every day, and every employee; and 'C' stands for control (every task is controlled) and also for 'clear' (in the sense of clearing up every daily task before the end of each day). Targets are given to each employee at the start of their daily shift, and they must meet or exceed these targets, while simultaneously maintaining 
required levels of quality and orderly behaviour, if they want to receive their full salary. Bonuses and promotions are given to employees who consistently exceed their daily targets. Those who fall short have their pay docked or are demoted to probationary status. One key feature of the OEC system is that employees find out immediately at the end of each shift how their performance has affected their financial remuneration for that day. When combined with the various positive and negative reinforcing rituals mentioned earlier, this gives them a major incentive to perform at a high level every day. Another key feature is that employees are expected to improve their overall performance on average by $1 \%$ each day. This encourages them to constantly look for ways to increase their own efficiency and that of their work teams by suggesting changes to production processes or innovations that save the firm time and money (X. Ren 2007; Lin 2005).

While Haier's OEC system led to increased efficiency during the 1980s and 1990s, as the firm grew larger and hired more staff, it became more difficult to align the targets for individual employees with the market. For example, the firm's fridge division could efficiently produce millions of high quality fridges, but if there was not enough demand from customers, that work would be wasted. To avoid these kinds of inefficiencies, the firm needed a system that would reward each employee based primarily on the market performance of products in which they had been involved (R. Zhang 2000b).

So since 1998, Haier has modified the OEC system into the so-called SBU system. Whereas businesses have traditionally been divided into strategic business units (SBUs) based on products and/or functions (Hammer 2001, 129-36), under Haier's version every 
employee would be treated as an SBU, or "little boss," with “zero distance from the firm’s customers” (R. Zhang 2002a). Since not every employee would have direct contact with the firm's external customers, in practice the "customers” of each employee are the next people down the production chain within the firm, and the suppliers are the next people up the chain. Any failure by an individual employee to fulfill their part of the process in providing the correct products or to meet the contracted deadlines will allow the "customer” further down the chain to claim “compensation,” which means a deduction in the employee's remuneration. The firm has set up a sophisticated software system that tracks every employee’s contribution to this so-called "market chain” and provides them with a "profit and loss statement” every day to show how they are doing in terms of the market performance of products in which they are involved (Liu 2006, 11738; Lin 2009, 46-8).

Even non-manufacturing divisions of the firm, such as human resources, are included in the SBU system. This means that they must hire and train employees for the firm's various divisions who will perform satisfactorily in their allocated jobs. If they supply employees that are substandard, their “customers” in the firm's other divisions can seek compensation from the human resources division (Liu 2006, 126-7).

Haier's SBU system provided the financial incentives for the firm's employees to engage in a group-wide effort at business process reengineering and lean manufacturing with just-in-time production and “zero inventories,” inspired by the writings of Michael Hammer and James Champy (1993). According to Zhang Ruimin, the system is designed 
not to make employees meet their targets in a mechanical, unreflective way, but to change their whole mindset from that of workers to market-conscious "bosses" (R. Zhang 2002a, 2002b).

Huawei has also adopted its own sets of management and process systems, and updated them over the years to inculcate its cultural values, with similar impressive financial results as those at Haier (Z. Ren 1995; 2000a; G. Zhang 2007, 73-5, 230-2; Y. Wang 2007, 100-4, 178-80). To avoid repetition, we will not examine these in detail. What is clear about the various reforms undertaken by both these firms is that their CEOs have played a pivotal role in seeing the need for reform in the first place, and taking a close interest in the reform process to ensure it is more than just half-hearted lip service to fashionable new management concepts: that it is actually implemented at the level of every manager and employee.

E. Leading by example: the role of the CEO

All corporate culture theorists emphasize the crucial role played by a firm's CEO (who may also be the firm's founder) in fixing and shaping the firm's culture, and just as important, in refusing to allow managers and employees to lose sight of positive cultural values as the firm grows (Schein 1985, ch.10). Put another way, when systems that worked well for building cultural values at an earlier stage are no longer appropriate for fostering those values at the next stage of development, it is up to the CEO to jettison those systems and find new ones that work better. 
One character trait that is shared by Zhang Ruimin and Ren Zhengfei as CEOs is their ability to evoke a constant sense of crisis and palpable fear of complacency in their employees. This in turn allows them to push through fundamental reforms to take their firms' growth to the next level. As early as 1996, Ren Zhengfei was expressing his concerns about Huawei's success in a speech to the firm's prizewinning employees. His remarks must have dampened the joyful atmosphere of the proceedings like a wet blanket:

Huawei is already in a period of ascendency, and this might easily make us think that the bitter and hard battles of the last eight years are over and that we are now victorious. This is extremely frightening! We still fall far short of many other Chinese and foreign firms, and only by continuing to engage in fierce mental struggle ... will we manage to avoid destruction (Z. Ren 1996a).

Ren has continued to make such predictions of imminent doom consistently over the past fifteen years, despite Huawei’s incredible growth (see, for example, Z. Ren 2001, 2008).

Zhang Ruimin has made similar comments, although not as dramatically as Ren Zhengfei. For example: “It's very easy to allow your success to defeat you ... It's really important to know how to avoid being blinded by success, and the way we do that is by requiring everyone to constantly conquer themselves” (R. Zhang 2002a). 
Presumably this sense of crisis, of total collapse just around the corner, is a sincere expression of these two CEOs' outlook, no matter how paranoid it appears to outside observers. And whether or not the employees at Haier and Huawei enjoy working in such a high pressure environment, one thing they cannot deny is that their CEOs are tirelessly working for their firms too, often at the expense of their families and their own health (Yi and Ye 2003, 67, 172; G. Zhang 2007, 72-3, 220). They model their firm’s culture and values in their own behaviour.

Another key characteristic that Zhang and Ren share is their pragmatic openness to any management method that works. Zhang’s speeches and interviews are peppered with references to management gurus like Michael Porter, Peter Drucker and Michael Hammer, and to the practices of foreign firms like Toyota, Matsushita and GE (R. Zhang 2002b; Yi and Ye 2003, 185-6). Ren Zhengfei has hired international consulting firms like IBM and the Hay Group to advise on Huawei’s product development and human resources restructuring, and his speeches are full of the latest jargon showing that he too is a voracious student of management theory (Z. Ren 1995; 2000a; G. Zhang 2007, 73-5).

At the same time, they realize that foreign methods cannot be blindly imported without modification: they need to be adapted to the individual Chinese firm's context and expressed in terms of traditional or "revolutionary” Chinese ideas (R. Zhang 1998, 2002b; Z. Ren 2000b). 


\section{Negative Aspects of Corporate Culture Transformation}

Haier and Huawei have certainly achieved impressive growth and profitability over the past two or more decades, and some of this performance is doubtless due to the techniques of cultural management identified above. Their success has not gone unnoticed by other Chinese business leaders and by the Chinese government. Haier's inhouse training centre, Haier University, has offered courses in the “Haier Way” to thousands of managers from other Chinese firms, and both Haier and Huawei are regularly cited in Chinese business textbooks and studied as successful cases in business schools. The excellent performance of these two firms and others that adopted similar cultural transformation programs was a major factor in SASAC's decision to introduce its 2005 policy to promote corporate culture in China’s largest state-controlled corporate groups (R. Wang 2005).

Yet their success has also come at a high cost, and it is arguable that the very cultural values that have dramatically improved these two firms' financial performance have also created serious problems among their workforces, and may obstruct their ability to sustain their international growth.

The first major issue that both these firms must address is how to deal with their growing workforces, and the cultural difficulties of employing increasing numbers of overseas employees as they expand into numerous countries. In their initial periods of growth, both Huawei and Haier have relied on draconian systems of rewards and penalties to 
mold the behaviour of their employees and to inculcate their core values. Both firms were greatly assisted in this endeavour by the protected status of the Chinese market, and the enormous growth potential that it provided. As long as they rewarded their employees more generously than other Chinese firms, and kept their focus on improving quality, innovation and customer service, they could stay ahead of the competition and remain extremely profitable. Their employees did not complain, because they knew that their situation was better than the vast majority of Chinese employees, particularly those who were stuck in the millions of exploitative export-processing factories in China's coastal regions (G. Zhang 2007, 232).

But as China has opened up its markets to more foreign investment since 2001, and other Chinese firms have adopted similar cultural practices and started nipping at these firms' heels, they have been forced to expand overseas and develop higher-end technologies. To do this requires a greater proportion of highly-skilled and educated employees from many different countries, who may be less willing to endure the military-style discipline, constant supervision, grueling working hours, and public humiliations that are a regular occurrence under both Haier and Huawei’s corporate cultures. Huawei has faced particular criticism in the Chinese media for its culture of overwork, especially since 2008, when a sixth young Huawei employee died of unnatural causes (including suicide and sudden unexplained seizures) within the space of two years (Yang 2008). Haier is not immune to such criticism either: many former Haier employees have noted its "culture of cursing," where managers berate employees for their failure to outperform daily targets (Deng 2004, 87). 
It is particularly worrying that both firms have seen a high turnover of experienced personnel in recent years, as many of these employees have gone to work at competing firms (Ran 2005; Deng 2004, 87-8; G. Zhang 2007, 246-7). This suggests that these firms’ high salaries and bonuses are not enough to counterbalance employee stress and tension-filled working environments. Huawei’s controversial decision to avoid giving long-term contracts to its senior employees under China's new Labour Contract Law (2008) did not help its public reputation either, and doubtless was highly unpopular among its own workforce too, despite being consistent with the firm's cultural practice of pay for performance and firing unproductive workers (Anon. 2007a, 2007b).

The second issue is that large Chinese corporations like Huawei and Haier are generally viewed by overseas policy-makers and media as too strongly influenced by the Chinese government. This means that their potential to expand their global reach and improve their core technologies through foreign acquisitions may be seriously curtailed. Haier has not yet encountered serious problems in this respect, as its products are not politically sensitive. ${ }^{5}$ But Huawei, despite being a privately-controlled firm, has faced enormous suspicion, as its line of business includes sophisticated communications systems that could potentially have military applications. Its attempt to acquire 3Com in the U.S. failed in 2008 after CFIUS failed to approve it on national security grounds; and while it has managed to obtain lucrative telecom supply contracts in Holland and the U.K., it

\footnotetext{
${ }^{5}$ Haier’s failure to acquire Maytag was apparently due to economic, not political reasons (Lenard 2005).
} 
regularly faces accusations in the international press of secretly working to promote the interests of the Chinese military or the CCP. ${ }^{6}$

Part of this problem is due to geopolitical and historical factors and ingrained prejudices over which Chinese firms have no control. There is little factual basis for the speculation that Huawei has close ties with the Chinese military or the CCP (G. Zhang 2007, 20, 556, 134-5). But Huawei’s refusal to clarify its true ownership has definitely added fuel to the speculation that it has something to hide. Huawei’s senior management apparently fears that if it revealed who actually holds the firm's shares, it would face a flood of lawsuits from former employees who have been shortchanged by the company (Deng 2004, 37). According to Huawei’s registration records, 99.9\% of the shares are held by the firm's employee share fund. Employees receive regular distributions from the fund, but they are not told how those distributions are calculated (G. Zhang 2007, 251). This system allows Huawei’s leadership discretion in dividing up the firm’s profits to employees based on their performance or re-investing them in the firm's business, which has helped to greatly reduce the firm's costs. But the secrecy surrounding the system has led to dissatisfaction from former and current employees and to suspicion among foreign government officials and commentators that Huawei is simply trying to hide its military and Communist Party connections behind the convenient front of an "employee share ownership fund.”

\footnotetext{
${ }^{6}$ For typical reports, see Anon. 2007c and Dean 2008. The main "evidence" in these reports is that Huawei is not "transparent" about its ownership, that Ren Zhengfei was formerly a PLA soldier before he founded the firm, and that Huawei's communication products can be used for military as well as civilian purposes, none of which is particularly conclusive. Most of these reports quote a 2005 study by the RAND Corporation (Medeiros 2005), which itself relies largely on unnamed sources.
} 
Firms like Huawei could significantly improve their international image by adopting more transparent reporting practices, disclosing their ownership structures completely, and introducing effective policies to ensure that the business really is managed independently from the government. But this would require a loosening of the culture of top-down financial control at the firm.

A final issue that may hamper the growth of these two firms is a tendency to pressurize employees into squeezing out short-term gains that may result in long-term damage to their businesses. In the case of Haier, this has resulted in extreme diversification into sectors in which the firm has little aptitude or experience. Haier has used up significant resources attempting to expand into computers, mobile phones, furniture, pharmaceuticals, and foodstuffs, none of which have produced adequate returns on their investments (Deng 2004, 81-2). Haier’s apparently random diversification strategy partly stems from its SBU system. This incentive system encourages all employees to become entrepreneurs and to develop products in any line of business, as long as it is profitable for the firm. But it almost inevitably leads to a mass of new products for which there is only a narrow short-term demand. This may be justifiable within China’s domestic market, where even niche products can generate satisfactory revenues due to the enormous population. But in more mature (and smaller) Western markets, it looks like a strategy for short-term gain at the expense of long-term growth. At its worst, the profusion of hastily developed products and services may result in the erosion of Haier's hard-won brand reputation for quality (Deng 2004, 72-5). By contrast, Huawei’s problem is not diversification so much as intellectual property disputes. The firm has been plagued 
by lawsuits both within China and overseas, alleging that Huawei stole the I.P. of other firms, including such high-profile multinationals as Cisco Systems and Motorola (Wahba and Lee 2010). Whatever the merits of such lawsuits, it is easy to infer that the high pressure placed on Huawei's employees to constantly innovate and rapidly produce marketable products may have led some of them to take short cuts and infringe the I.P. rights of other technology firms.

\section{Conclusion and Limitations of This Study}

We have described the cultural management techniques by which Haier Group and Huawei Technologies claim to have improved their employees’ performance and transformed their firms into internationally competitive businesses. We also identified several negative aspects of these firms' development that can be at least partly attributed to their cultural values, and that may obstruct their future potential unless efforts are made to adjust their values and implement corresponding new incentive systems. Of course, this is an ongoing process. Thus one of the limitations of the current study is that it is too early to see how successful Haier and Huawei will become on the international stage, or how they will adapt their cultures to deal with a truly multinational workforce. Follow-up studies will need to be done in a few years time to answer these questions. A second limitation is that this study only looks at two firms, and therefore cannot draw broader conclusions about Chinese corporate culture and how it may differ from corporate culture practices in other countries, or how Haier and Huawei differ from other Chinese firms. Yet it is clear that cultural management is a major preoccupation of Chinese government and business leaders (Cooke 2008; Buckley et al 2008, 43-5). Thus, 
further empirical research into the cultural management practices of other Chinese firms and the impact of the Chinese government on corporate culture promotion is required to round out the picture and to assess whether these practices will have a positive impact on the performance and organizational transformation of Chinese firms. 


\section{References:}

Anon. 2007a. Huawei cizhi fengbo yu lao yuangong de hetong weiji. Xinhuanet (5 November), online at http://news.xinhuanet.com/employment/200711/05/content_7012267.htm

Anon. 2007b. Zhuizong baodao: Huawei fouren guibi Laodongfa. Xinhuanet (5 Nov. 2007), at http://news.xinhuanet.com/employment/200711/05/content_7012305.htm.

Anon. 2007c. 3Com Huawei transaction to be reviewed by CFIUS. Tech Law Journal (9 October): http://www.techlawjournal.com/topstories/2007/20071009b.asp.

Buckley, Peter J. , Jeremy Clegg, and Tan Hui. 2008. Organization and action in a Chinese state-owned service intermediary: the case of Sinotrans. Journal of Chinese Economic and Business Studies 6: 1, 23-48.

Cooke, Fang Lee. 2008. Enterprise culture management in China: insiders’ perspective. Management and Organization Review 4.2: 291-314.

Deal, Terrence E. and Allen A. Kennedy. 1982. Corporate Cultures: The Rites and Rituals of Corporate Life. Reading, Mass.: Addison-Wesley Pub. Co.

Dean, Jason. 2008. Outside of U.S., few fear Huawei. Wall Street Journal (Asian edition). 22 February.

Deng Ping. Ed. 2004. Zhongguo qiye bingxiang baogao. Shanghai: Xuelin chubanshe. Du, Yuping. 2003. Haier's survival strategy to compete with world giants. Journal of Chinese Economic and Business Studies. 1.2: 259 - 266.

Frankel, Alex. 2007. Punching In: One Man's Undercover Adventures on the Front Lines of America's Best-Known Companies. New York: HarperCollins. 
Haier. N.d.(a). Gongsi jianjie. Online at http://www.haier.cn/about/about.shtml.

Haier. N.d.(b). Values and philosophy. Online at http://www.haier.com/abouthaier/CorporateCulture/index.asp.

Haier. N.d.(c). Leadership. Online at http://www.haier.com/abouthaier/CorporateProfile/leadership.asp.

Haier. N.d.(d). Pictures and words. Online at http://www.haier.com/abouthaier/CorporateCulture/workforce.asp

Hammer, Michael, and James Champy. 1993. Reengineering the corporation: $a$ manifesto for business revolution. New York: HarperCollins.

Huawei. N.d.(a). Quanqiu yunying. Online at: http://www.huawei.com/cn/corporate_information/global_operations.do

Huawei. N.d.(b). Hebing caiwu baobiao zhaiyao ji jizhu. Online at: http://www.huawei.com/cn/corporate_information/huawei2009/financial_statement s_summary.do

Huawei Technologies. 1998. Huawei basic law. Copy on file with authors.

Jackson, Sukhan. 1992. Chinese enterprise management: reforms in economic perspective. Berlin; New York: W. de Gruyter.

Jiang, Qiang and Li Yuan. 2007. Huawei buchang shiyi yuan guli qiqian ming lao yuangong cizhi. Xinhuanet (2 November), online at http://news.xinhuanet.com/employment/2007-11/02/content_6996878.htm

Jones, Quentin, Dexter Dunphy, Rosalie Fishman, Margherita Larne and Corinne Canter. 2006. In great company: unlocking the secrets of cultural transformation. Melbourne and Auckland: Human Synergistics. 
Kilmann, Ralph, Mary J. Saxton and Roy Serpa, eds. 1986. Gaining control of the corporate culture. San Francisco: Jossey-Bass.

Lenard, David M. 2005. Rocky waters for China's US acquisitions. Asia Times Online (July 22): http://www.atimes.com/atimes/China/GG21Ad03.html.

Lin, Thomas W. 2005. OEC management-control system helps China Haier Group achieve competitive advantage. Management Accounting Quarterly 6.3: 1-11.

Lin, Thomas W. 2006. Lessons from China. Strategic Finance (October): 48-55.

Lin, Thomas W. 2009. Haier is higher: a Chinese company’s roadmap to success via its reengineering system. Strategic Finance (December): 41-49.

Liu, Jinxian. 2006. Zizhu chuangxin: Haier zhi hun. Beijing: Zhishi chanquan chubanshe.

Luo, Changhai, Chen Xiaoming, Xiao Chunyan, and Guo Canxi. 2006. Qiye wenhua jianshe ge'an pingxi. Beijing: Tsinghua University Press.

Medeiros, Evan S., Roger Cliff, Keith Crane, and James C. Mulvenon. 2005. A new direction for China's defense industry. Arlington, Va.: RAND Corporation.

Ouchi, William. 1981. Theory Z: how American business can meet the Japanese challenge. Reading, Mass.: Addison-Wesley.

Parker, Martin. 2000. Organizational culture and identity: unity and division at work. London; Thousand Oaks, Calif.: SAGE.

Ran Mengshun. 2005. Huawei Gangwan zhizheng: Ren Zhengfei yu Li Yinan cong shisheng dao duishou. Nanfang zhoumo. (22 September).

Ren, Xiyuan. 2007. OEC: Haier riqing gongzuofa. Beijing: Zhongguo yanshi chubanshe. Ren, Zhengfei. 1995. Zai di si jie guoji dianzi tongxin zhan Huawei qingzhu jiuhui shang de fayan. Huawei ren 23 (30 November). 
Ren, Zhengfei. 1996a. Fanjiao poman, zai sixiang shang jianku fendou. Huawei ren 26 (2 May).

Ren, Zhengfei. 1996b. Zailun fanjiao poman, zai sixiang shang jianku fendou. Huawei ren 31 (18 July).

Ren Zhengfei. 1997a. Buyao wangji yingxiong. Huawei ren 42 (30 January).

Ren, Zhengfei. 1997b. Ziyuan shi hui kujie de, weiyou wenhua cai neng sheng sheng bu xi. Huawei ren 46 (20 March).

Ren, Zhengfei. 2000a. Weishenme yao ziwo pipan: zai zhongyanbu jiang daisiliao zuowei jiangjin jiangpin fagei yanfa gugan dahuishang de jianghua. Huawei ren 109 (22 September).

Ren, Zhengfei. 2000b. Chuangxin shi Huawei fazhan de bujie dongli. Huawei ren 107 (20 July).

Ren, Zhengfei. 2001. Huawei de dongtian. Copy on file with authors.

Ren, Zhengfei. 2008. Jinqi zai canjia gongsi youxiu dangyuan zuotanhui shi fayan. Copy on file with authors.

Schein, Edgar H. 1985. Organizational culture and leadership: a dynamic view. San Francisco: Jossey-Bass.

Sheldrake, John. 2003. Management Theory. $2^{\text {nd }}$ edition. London: Thomson.

Smith, Peter B, David C Thomas and Mark F Peterson. Eds. 2008. The handbook of cross-cultural management research. Thousand Oaks : Sage Publications.

State-owned Assets Supervision and Administration Commission of the State Council (SASAC). 2005. Guanyu jiaqiang Zhongyang qiye qiye wenhua jianshe de zhidao 
yijian. Issued by SASAC’s Propaganda Department. Online at:

http://www.sasac.gov.cn/gzjg/xcgz/200504190137.htm

Teagarden, Mary B., and Dong Hong Cai. 2009. Learning from dragons who are learning from us: developmental lessons from China’s global companies. Organizational Dynamics 38.1: 73-81.

Tsui, Anne, Hui Wang and Katherine R Xin. 2006. Organizational culture in China: An analysis of culture dimensions and culture types. Management and Organization Review 2: 345-76.

Tung, Rosalie. 1982. Chinese industrial society after Mao. Lexington, Mass.: Lexington Books.

Wahba, Phil, and Melanie Lee. 2010. Motorola sues Huawei for trade secret theft. Reuters online (Jul 22): http://www.reuters.com/article/idUSTRE66L0J220100722

Wang, Ruixiang. 2005. Wang Ruixiang jiu ‘Guanyu jiaqiang zhongyang qiye wenhua jianshe de zhidao yijian’ da jizhe wen. 2 June. SASAC Publicity Office, online at: http://www.sasac.gov.cn/n1180/n1566/n259730/n264213/1872925.html

Wang, Yongde. 2007. Langxing guanli zai Huawei. Wuhan: Wuhan daxue chubanshe. Wu, Jianguo. 2004. Huawei qing huang bujie: jiti cizhi yu neibu chuangye jienanti. IT jingli shijie. 4 March. Online at http://tele.pconline.com.cn/pl/0403/327528.html

Xin, Katherine R, Anne S Tsui, Hui Wang, Zhi-Xue Zhang and Wei-Zheng Chen. 2002. Corporate culture in state-owned enterprises: an inductive analysis of dimensions and influences. In Anne Tsui and C M Lau, eds., The management of enterprises in the People's Republic of China: 415-41. Boston: Kluwer Press.

Yang Jiang. 2008. Miwu zhong de Huawei zishamen. Xinmin zhoukan. (2 April): 17-27. 
Yi, Jeannie J. and Shawn X. Ye. 2003. The Haier way: the making of a Chinese business leader and a global brand. Dumont, N.J.: Homa \& Sekey Books.

Zhang, De, ed. 2002. Qiye wenhua jianshe. Beijing: Tsinghua University Press.

Zhang, Guanjing. 2007. Huawei si zhang lian. Guangdong: Jingji chubanshe.

Zhang, Ruimin. 1998. Kaituo chuangxin - qiye fazhan de dongli ziyuan, pp.330-345 of China Corporate Culture Institute, ed., Qiye wenhua zai zhongguo. Beijing: Guangming ribao chubanshe.

Zhang, Ruimin. 2000a. Zai shijie shangxueyuan gaoji jingliren jiaoyu lianmeng 2000 nian nianhui (April 5). Copy on file with authors.

Zhang, Ruimin. 2000b. Zai Haier chuangye 16 zhou nian, shixian quanqiu yingye’e 406 yi yuan fazhan yantaohui (26 December). Copy on file with authors.

Zhang, Ruimin. 2002a. Haier quanmian shishi guojihua zhanlue de silu (26 December). Copy on file with authors.

Zhang, Ruimin. 2002b. Zai Jingji ribao Haier zaizao yantaohui shang de jianghua (June). Copy on file with authors.

Zhang, Ruimin. 2003. Zhang Ruimin shouxi zhixingguan chuxi di baci zhongri chanye yantaohui fayan tiyao (November). Copy on file with authors.

Zhang, Ruimin. 2008. Meiyou gaige kaifang jiu meiyou Haier: zai Qingdao shi jinian gaige kaifang 30 zhou nian zuotanhui shang de fayan (December). Copy on file with authors.

Zhang, Xibao. 2009. Values, expectations, ad hoc rules, and culture emergence in international cross-cultural management contexts. New York: Nova Science Publishers. 
Zhao, Jijun 2005. Ganwu Huawei wenhua. Huawei People 164 (10 June).

Zhonghua qiye wenhua wang (Chinese Corporate Culture Network). 2006. Quanguo

shouqi qiye wenhua shi guojia zhiye zige renzheng 5 yue 29 ri zai jing jieye. Posted

2 June, at http://www.sinoec.net/Article/cco/report/Article_2567.html.

Zhongguo qiye wenhua yanjiuhui (China Corporate Culture Institute), ed. 2003-

[biannual volumes]. Zhongguo qiye wenhua nianjian. Beijing: Enterprise

Management Publishing House. 